\title{
BMJ Open Qualitative study exploring the factors influencing physical therapy management of early knee osteoarthritis in Canada
}

Crystal MacKay, ${ }^{1}$ Gillian A Hawker, ${ }^{2,3}$ Susan B Jaglal ${ }^{1,3,4}$

To cite: MacKay C, Hawker GA, Jaglal SB. Qualitative study exploring the factors influencing physical therapy management of early knee osteoarthritis in Canada. BMJ Open 2018;8:e23457. doi:10.1136/ bmjopen-2018-023457

- Prepublication history and additional material for this paper are available online. To view these files, please visit the journal online (http://dx.doi. org/10.1136/bmjopen-2018023457).

Received 6 April 2018

Revised 24 July 2018

Accepted 11 October 2018

Check for updates

(c) Author(s) (or their employer(s)) 2018. Re-use permitted under CC BY-NC. No commercial re-use. See rights and permissions. Published by BMJ.

${ }^{1}$ Toronto Rehabilitation Institute, University Health Network,

Toronto, Ontario, Canada

${ }^{2}$ Department of Medicine, University of Toronto, Toronto, Ontario, Canada

${ }^{3}$ Institute of Health Policy, Management and Evaluation, University of Toronto, Toronto, Ontario, Canada

${ }^{4}$ Department of Physical Therapy, University of Toronto, Toronto, Ontario, Canada

Correspondence to Dr Crystal MacKay; crystal.mackay@utoronto.ca

\section{ABSTRACT}

Objectives Increasingly, there is emphasis on identifying and initiating treatment of osteoarthritis $(O A)$ in the early phases of the disease. This study aimed to identify the perceived barriers and facilitators to managing clients with early knee $\mathrm{OA}$ and the contextual factors affecting implementation of care by physical therapists (PTs). Design Qualitative study using in-depth semistructured interviews with 33 PTs. The interviews were audiorecorded, transcribed verbatim and analysed inductively using thematic analysis.

Setting Canada.

Participants A purposive sample of PTs who managed clients with knee symptoms and/or diagnosed knee OA in community/outpatient settings in three provinces in Canada (Ontario, Alberta, British Columbia).

Results Factors that affected physical therapy management of early knee $0 \mathrm{~A}$ were identified at four levels: the community, healthcare system, healthcare provider and client level. Some healthcare provider factors acted primarily as enablers of management, such as PTs' confidence in their ability to manage perceived early knee OA, PTs' beliefs about consequences of $0 \mathrm{~A}$ and the PT scope of practice. However, the study illuminated a range of modifiable factors that can act as barriers to management. These factors included access to services in the community and healthcare system; healthcare provider factors such as time, access to evidence and physician's role in referrals and messaging; and client factors related to client characteristics (eg, general health, socioeconomic status), engagement in management and beliefs about $0 \mathrm{~A}$. Conclusion These findings provide us with a basis to begin to address specific barriers and to optimise care for early knee $\mathrm{OA}$.

\section{INTRODUCTION}

Osteoarthritis (OA) is highly prevalent and a leading contributor to global disability. It is estimated that $9.6 \%$ of men and $18.0 \%$ of women over 60 years of age have symptomatic OA worldwide. ${ }^{2}$ The knee accounts for $83 \%$ of OA disability. ${ }^{1}$ There is no cure for OA but there is strong evidence that exercise and weight loss reduce pain and disability. ${ }^{34}$ All clinical guidelines recommend

\section{Strengths and limitations of this study}

- This study contributes an in-depth understanding of the factors influencing management of early knee osteoarthritis (OA) by physical therapists (PTs), providing us with a basis to begin to address specific implementation problems.

- Various strategies were employed to enhance rigour in the study, including detailing the study methods, use of an audit trail, iterative data collection and analysis, and use of thick description of findings.

- Since there was no universally agreed upon definition of early knee $\mathrm{OA}$ at the time of the study, we focused on what participants perceived as early knee $O A$ and used vignettes to help guide discussions about management.

- Participants in this sample worked in various practice settings in three provinces of Canada; however, they were experienced PTs and their perceptions may not reflect the perspectives of PTs in all healthcare systems.

non-pharmacological

interventions, including education, exercise and weight management, as first-line management. ${ }^{5-8}$ Yet, research has shown that the care received by people with $\mathrm{OA}$ in primary care often varies from clinical guidelines. ${ }^{9-11}$ In a systematic review of studies comparing OA quality indicators to community-based clinical practice, pass rates for first-line non-pharmacological approaches (eg, exercise, education) were, on average, below $40 \% .^{9}$ Achievement of quality indicators has been shown to be worse in younger people and people with less severe symptoms. ${ }^{12}$ This is consistent with qualitative research from the patient's perspective that has shown that working age adults with mild-to-moderate knee OA symptoms reported limited professional guidance and support. ${ }^{13}$ Given the growing awareness of the importance of identifying and initiating treatment in the early phases of OA, ${ }^{1415}$ it is critical to begin to address this practice 
gap. Intervening early in the disease has potential to help control OA pain and disability and reduce work loss.

Physical therapists (PTs) are central to the non-pharmacological management of OA symptoms through the design and delivery of exercise programmes. ${ }^{16-18}$ While prior research found that PT management of OA varies from evidence-based care delivered in clinical trials, ${ }^{19}$ there is limited information on the barriers and facilitators to providing OA care from the perspective of $\mathrm{PTs}^{20}$ particularly for management of early OA. As a first step towards optimising clinical care, this research sought to identify the barriers and facilitators to managing clients with perceived early knee $\mathrm{OA}$ and the contextual factors affecting implementation of care from the perspective of PTs considering the community, health system, healthcare provider and patient.

\section{METHODS}

\section{Study design}

We conducted a qualitative descriptive study. Qualitative description is a qualitative method, which produces a comprehensive summary of a phenomenon in everyday terms, with analysis and interpretation of the findings remaining closer to the data. It draws on the tenets of naturalistic inquiry in which researchers study a phenomenon in a manner as free of artifice as possible, without any intervention or alteration by the researcher. ${ }^{21}$

We followed the Consolidated Criteria for Reporting Qualitative Studies guidelines for reporting qualitative research. $^{22}$

\section{Sampling and data collection}

Participants were recruited via emails to members of the Orthopaedic Division, Canadian Physiotherapy Association and using a snowball technique. Interested individuals contacted the first author (CM) by email or phone. The first author followed up with potential participants by telephone to answer any questions, screen participants for eligibility and arrange a time for an interview. Registered PTs were eligible if they: (1) worked with individuals with knee symptoms (ie, pain, aching, stiffness) or diagnosed knee OA in the past 3 months, (2) worked in community-based or outpatient settings (eg, private clinics, primary care practice, hospital outpatient departments) and (3) could communicate in English. All participants indicated they worked with clients with perceived early knee OA. Participants in three Canadian provinces (British Columbia, Alberta, Ontario) were purposively sampled to ensure variation in practice setting (eg, private/public) and geographical location. A semistructured interview guide was developed and pretested prior to commencing interviews (online supplementary file). The interview guide was constructed to begin with general questions about the PTs practice and their perceptions of OA. We inquired about participants' experiences working with clients with early knee OA and their approach to management of these clients. The interview guide included two patient vignettes, which were developed using scientific literature, data from a qualitative study of people with mild-to-moderate knee symptoms ${ }^{23}$ and clinical input from PTs. Participants were asked how they would approach management of each clinical scenario. Finally, participants were asked about the barriers they faced providing support for people they perceived to have early knee OA and what helped them provide support to this population. The Theoretical Domains Framework (TDF) helped guide development of interview questions and probes. The TDF is an integrative framework of theories of behaviour change which has been used in several studies to identify barriers and facilitators of health professional clinical behaviours. ${ }^{24-26}$ The TDF was rigorously developed and validated; it has 14 domains. ${ }^{27} 28$

The first author, CM, a postdoctoral fellow who has graduate training and experience in conducting qualitative research, conducted the interviews. The interviewer was a PT who had worked in the field of arthritis research for several years and had a particular interest in OA. However, she had not worked directly with any of the study participants. Interviews were conducted by telephone or in person with only the interviewer and participant present. In-person interviews occurred in a private room at the participants' place of work or at the university. The literature supports the use of both face-to-face and telephone interviews within the same study while maintaining the trustworthiness of the findings. ${ }^{29}$ Interviews lasted approximately $60-75 \mathrm{~min}$. Thirty-three PTs from three provinces in Canada participated in the study (table 1). Twenty-four participants worked in private practice in the community (clients were self-referred to their services or were referred by a physician, typically a primary care physician); nine participants worked in publicly funded settings, including primary healthcare teams and hospital outpatient departments. Data collection ceased when no new responses or factors were identified.

\section{Analysis}

Data collection and analysis were conducted iteratively. Interviews were digitally recorded and transcribed verbatim by a professional transcriptionist. A qualitative

\begin{tabular}{ll}
\hline Table 1 Participant characteristics & \\
\hline & N \\
\hline Years in practice (mean, range) & $21(1-45)$ \\
Female/male & $25 / 8$ \\
Practice location & \\
$\quad$ Ontario & 23 \\
Alberta & 5 \\
$\quad$ British Columbia & 5 \\
Type of practice & \\
$\quad$ Publicly funded setting & 9 \\
\hline Private clinic & 24 \\
\hline
\end{tabular}


software program, NVivo 10, was used to organise data. Inductive thematic analysis as described by Braun and Clarke $^{30}$ was conducted. Two researchers (CM, SJ) met regularly to discuss their interpretations of the data. The first author inductively developed an initial coding framework. A second researcher independently coded a subset of transcripts (21\%) and the researchers met to compare codes. Through these meetings, the coding framework evolved. The codes were then organised into groups and common themes were identified. During the process, the research team met to discuss the analysis and alternative interpretations of the data. Field notes were written after interviews and memos were written to support formulation and revision of codes/themes. The documentation of reflections and thoughts related to interviews, interpretations of the data and developing concepts helped to promote reflexivity. An audit trail was maintained to enhance trustworthiness of the analysis.

\section{Patient and public involvement}

This research question was informed by a study of the perceptions and experiences of people living with symptoms of early knee OA. ${ }^{1323} 31$ People with perceived early knee OA were not involved in the study design or conduct of the study. PTs with clinical expertise in OA care were consulted in the process of developing the research methods. A lay summary of the study findings will be disseminated to study participants.

\section{RESULTS}

Factors that influenced management of perceived early knee OA were identified and organised into four

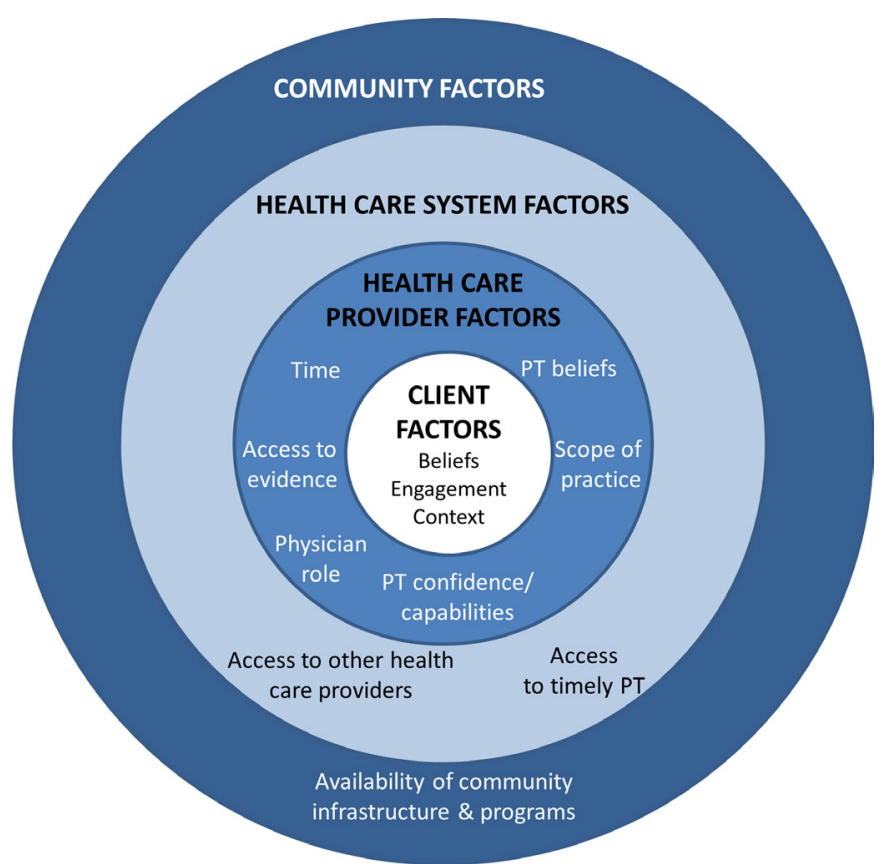

Figure 1 Factors which influence physical therapy management of early knee osteoarthritis. PT, physical therapist. categories: the client, healthcare provider, healthcare system and community (figure 1). There was variation in how these factors influenced OA management, such that a factor could act as a facilitator or a barrier to management in different contexts. When specific conditions (eg, practice setting, rural/urban location) explained the variation in how these factors influenced management, this is indicated in the results. Illustrative quotes are in table 2.

\section{Community factors}

Availability of community infrastructure and programmes

Participants consistently recommended clients participate in physical activity and exercise programmes to manage their knee symptoms. They often highlighted the benefits of having the infrastructure (eg, gyms, pools, walking/biking paths) and programmes (eg, exercise classes) available in their communities for their clients during the intervention period and following discharge. For example, one participant identified a community centre as a facilitator of management: 'They have a lot of aqua therapy type programs... They have a gym.' (PC10) In contrast, infrastructure or local programmes were lacking in other contexts, particularly rural settings. Some participants indicated that cost was a factor in whether their clients could access facilities/programmes. For example: 'Even $\$ 25.00$ at the local recreation centre for the year is just too much money for them.' (FHT2)

\section{Healthcare system factors}

\section{Access to timely physical therapy}

Access to physical therapy was consistently raised as a barrier to management. Canada's publicly funded healthcare system provides universal coverage for medically necessary hospital and physician services. Physical therapy services are provided in both public and private healthcare settings. The challenges identified by participants related to access were contingent on the type of practice. Participants in private practice expressed concern that people with no (or limited) extended health coverage or personal funds to pay out-of-pocket could not access services or delayed seeking help for early symptoms of OA. One participant explained: "Because people have to pay, I think people aren't getting early intervention. You always think, what if I could have seen this knee 2years ago." (PC22) Many participants also perceived that a lack of funding prevented clients from getting a full course of treatment. Some participants recounted how they worked with people to 'ration' their services based on the amount of funds available.

Availability and funding of publicly-funded services was limited (eg, restricted by age or income) in all provinces. Participants working in publicly funded settings (eg, hospitals, primary care practices) indicated that clients often had a waiting period before accessing care. Some participants triaged their caseload based on patient need such that people with chronic orthopaedic problems, like $\mathrm{OA}$, waited longer. Participants portrayed wait lists as a burden. One participant explained: "It's like a constant 
Table 2 Factors with sample quotes

Factors Sample quotes

Availability of community infrastructure and

"That's a great resource....certainly a lot of people keep going at the [community centre]." - PC10 programmes

Access to timely physical therapy "I think would be helpful, free access to the pool, free access to the gym. I think those things would really help people with early signs of OA." - PC20

\section{"If they're chronic, they could wait 4-6 months."-H01}

"Some people we can't get in or some people are under 65 and are not eligible for the funding and don't want to pay. So that's one barrier."-0001

"Here I have the luxury of its hospital funded so they don't have to pay so I can see them longer. In a private clinic I have to be considerate of they're paying, they have benefits, they have three more visits and their benefits are done so we try and finish up then or as best we can if they can't pay more."PC07

Access to other healthcare providers

"We have a dietician on staff. It's an easy referral if they would like to lose weight to help their knee pain."-FHT2

"We don't have one [dietician], and generally, I believe the family doctors will refer to a dietician." PC14

Physical therapists' confidence and "I have all the tools I need at my fingertips, my education and exercise components." - FHT2 perceived capability to "I feel very confident in treating the population. So, in that sense, I think my background helps me. I'm

manage early knee OA "I really believe that we can really help the people with OA, especially early on, to try to avoid going down that road."-PC24

Physical therapists' beliefs about the consequences of $\mathrm{OA}$ "Some do amazing, and so I don't know if that is the history of their disease process, anyway, or if it is because they are quite motivated to make a change."-PC23

"There are things we can do. I tell everyone that we can't undo any change that has occurred already but we can try to prevent further degenerative change." - PC02

Physician's role in "Their doctor says you've got arthritis, there's nothing you can do. The patient decides that they're referral and messaging going to stop physio."-PC4

to clients about OA "GPs don't have knowledge on what physios do or what other medical practitioners do, and they're still the gatekeepers."-PC09

"Well, the one frustrating thing that I find or challenging really is the somewhat inaccurate or dismissive approach from the family doctors based on x-rays. I find that very frustrating when people would come with obvious signs of osteoarthritis, symptomatically and in a clinical examination."-PC18

Scope of practice "I think it's helped me. I work within my scope of practice and anything that is outside of that, again, I refer them too. So, if patients are asking me about, exactly how do I lose weight, I can touch on the exercise part and give them a lot of advice about that. But if they're asking me about specific medications or drugs or supplements, I'll refer them to their family doctor or pharmacist." - PC13 "If I need an MRI, I don't often need one, but the odd time I think it may be helpful, I work under a medical directive for that." - $\mathrm{H} 01$

Time per Client "I'm really fortunate to have the time to treat people."-PC02

"Time is always an issue. I guess I just put it in the background. Sometimes you just have to, well I have to manage my time with each patient so sometimes somebody has to get less and somebody more..."-0001

\begin{tabular}{|c|c|}
\hline $\begin{array}{l}\text { Access to scientific } \\
\text { evidence }\end{array}$ & $\begin{array}{l}\text { "Unless you're working in an institution, where you do have access, private clinics are left by the } \\
\text { wayside... It costs a lot money to get an article sometimes." - PC19 } \\
\text { "We have access through the healthcare library, so I will do searches through that to find articles } \\
\text { on whatever topic I'm looking for. But then I physically have to go to the library at [university] to get } \\
\text { the articles. Most of the ones in the health library that you want to read, you can't read the whole } \\
\text { article."-PC12 }\end{array}$ \\
\hline $\begin{array}{l}\text { Client engagement in } \\
\text { therapy }\end{array}$ & $\begin{array}{l}\text { "Well, depends on the patient, there's patient personality, there's people who like passive treatment as } \\
\text { opposed to active treatment, that becomes a huge challenge."-FHT01 } \\
\text { "I try to educate them on the importance of doing it, but some people just don't ... they don't want to } \\
\text { do exercises. You can only ... you can bring the cow to the water, but you can't make it drink."-PC08 } \\
\text { "The compliance with their active exercise program, that's a huge barrier. The fact that they will start } \\
\text { feeling better and then they quit doing stuff, which is pretty much everybody I see that's come back, } \\
\text { that's the reason, usually."-PC19 }\end{array}$ \\
\hline
\end{tabular}


Table 2 Continued

\begin{tabular}{ll}
\hline Factors & Sample quotes \\
\hline Client beliefs about OA "So, I think that's public perception of what arthritis is and its potential to do well actually. Everybody \\
thinks they're doomed for a joint replacement or to suffer."-PC22 \\
"Then that might be a barrier in terms of their reluctance to exercise and to challenge that knee \\
because they're worried that things are going to deteriorate." - H04 \\
"I would say that the most frequent barrier that I come across is people's preconceived ideas about \\
either they've had someone in their family or they've seen another health professional before, a physio, \\
chiro, doctor, who has basically told them that they, you know, once you've had, quote/unquote, \\
"arthritis", you never get rid of it. Arthritis is forever, it just gets worse and worse."-PC01 \\
"English is a second language or they haven't mastered English or French. We have clinicians that \\
speak French. That's a bit of a barrier."-PC03 \\
"Some patients who just are experiencing such great poverty or other issues in their lives that they're \\
not able to do it. I have a lot of patients who live in the shelter system so they don't have anywhere to \\
exercise, which is just really tough." CHC1 \\
"People whose general outlook on life due to psychosocial influences. If they're depressed, if \\
they've got poor coping and poor support at home, and their attitude towards pain, their lack of \\
understanding. Education will take you so far, but if someone is really depressed, they're going to need \\
help in other aspects of their life before they can focus."-H04
\end{tabular}

GP, general practitioner; OA, osteoarthritis.

albatross on my back. I have about 65 people on a wait list...It's very rough." (CHC01)

\section{Access to other healthcare providers}

Access to other healthcare providers varied significantly and was a perceived facilitator of care for some participants and a barrier for others. Participants who had access to a team on-site or who had developed a network of healthcare providers they trusted tended to perceive this as a facilitator of management. One participant explained: "actually having the whole team of people, the naturopath, and the chiropractor, and massage therapist all working together, that's a big help." (PC08) Communication was central to facilitating care, with participants highlighting the importance of good working relationships and effective mechanisms to communicate (eg, phone, electronic medical record). When participants did not have access to other non-physician healthcare providers (eg, dietitian, naturopath), they were more likely to send clients back to the primary care doctor for support. For example: "No, we don't have a naturopath or dietician. If I thought it was an issue, I'd send them back to their GP, and see if they had resources." (PC16) Access to other healthcare providers was only identified as a barrier if they were unable to help clients access support and services they perceived to be necessary. For example, some participants identified lack of access to physicians with expertise in OA as a barrier.

\section{Healthcare provider factors}

PTs' confidence and perceived capability to manage early knee $0 \mathrm{~A}$ Participants consistently conveyed that they were confident in their capabilities and skills to help clients with perceived early knee OA using the strategies they believed to be effective within their scope of practice (eg, exercise, education, manual therapy techniques). They believed their training in orthopaedics made them well-suited to support this population. The following quote illustrates this confidence: "What obviously helps us is we have a huge orthopedic background. I think, to us, we are the experts in terms of providing care to this early knee OA." (FHT2) While many participants identified weight management as important, there was variability in their confidence to provide this support.

\section{PTs' beliefs about the consequences of $\mathrm{OA}$}

Central to participants' perceptions about early knee OA management, was a consistent belief that the treatment they provided could improve clients' symptoms (eg, reduce pain, increase function). Participants often indicated that clients 'do very well' with early intervention. Some participants believed treatment could potentially slow the progression of symptoms. One participant commented: "We're not curing arthritis, but we're just using certain things, usually exercise for the most part, to maintain function and hopefully prolong that worsening of symptoms." (PC24) However, participants believed without management, clients' symptoms were likely to progress, suggesting they may experience increased pain, reduced activity levels, weight gain and eventually require a joint replacement.

Physician's role in referral and messaging to clients about $\mathrm{OA}$ This factor represents the primary care doctor's role in management. The physician often was perceived to influence management through their role as a gatekeeper to services and their attitudes about OA. Physicians who did not make timely referrals to physical therapy were perceived to impede management. Participants also perceived that physicians' attitudes could influence clients' perceptions and their level of 'buy-in' to physical therapy. That is, physicians could negatively influence their patients by portraying OA as just part of 'getting older' and not supporting PT as a 'valid option'. In contrast, physicians who expressed support for physical 
therapy and exercise and referred clients to physical therapy early were perceived to facilitate management. One participant explained: "Some doctors are pretty knowledgeable and are sending us people early and appropriately but then on the flip side, the barrier is those doctors who don't get their clients in. They're not identifying that maybe physio could help. They're just saying... you know it's $O A$ and you're stuck with it." (PC03) While this factor was consistent across most accounts, a few participants de-emphasised physicians' influence because their clients primarily self-referred to physical therapy.

\section{Scope of practice}

The majority of participants indicated that their physical therapy scope of practice was adequate to manage clients with perceived early knee OA. However, a few participants suggested it would be useful to expand their scope of practice to include ordering diagnostic imaging: "It would be great if I could send people in for x-rays, I think it's a hindrance sometimes." (PC08) Regulations governing the ordering of diagnostic imaging vary across Canada. While some participants could order X-rays, the majority could not. Most participants did not view this as a barrier believing it was unnecessary to order an X-ray on a client with early knee OA. They explained that X-ray findings can be 'incongruent' with the clients' symptoms and were unlikely to change management. Participants who perceived X-rays to be useful mainly recommended them for clients who were not progressing as expected.

\section{Time per client}

Participants indicated that having adequate time to spend with clients was a facilitator of management. One participant reflected: "I think having someone actually just spend time, and listen to them, and help them work through some of the problems they're having, and find solutions for those problems, is helpful." (H02) Other participants were more restricted in the amount of time they could allot per patient. One participant explained that her growing wait list meant she would have less time with clients which she anticipated would affect her clients' outcomes.

\section{Access to scientific evidence}

Some participants identified access to current evidence as a factor in supporting management. Access to scientific literature was highly variable depending on the province and type of work setting. Some participants in private practice shared their challenges in accessing scientific papers: "I think that's a huge barrier because there are practitioners like me who are interested in reading the fine print of this study. The abstract doesn't give me enough information, and I'm not affiliated with the university." (PC06) One mechanism used to facilitate sharing of information was through professional networks or a 'community of practice'.

\section{Client factors}

Client engagement in therapy

All participants believed that client participation in management was critical to see improvement in symptoms. They indicated that a clients' 'motivation' to participate in management could be a barrier or facilitator and used terms such as 'buy-in' to indicate if clients were ready to engage in recommended therapy. Participants also indicated that maintaining management or 'sticking with it' (sometimes termed being 'compliant') was necessary for successful outcomes. Participants indicated that it was challenging work to get clients to initiate management and maintain it over the long term. One participant explained: "Then that's certainly challenging to people so those people need a lot of encouragement, education, and facilitation to try to get them adherent and onboard." (H04)

Participants' accounts suggested that challenges surfaced when there was a disconnect between the PTs' recommendations for treatment and the client's expectations or preferences for treatment (eg, PT recommended exercise/physical activity while the client preferred passive therapies). One participant recounted examples of clients who did not want to engage in an exercise programme and commented: "I don't know what you do as a physio then." (PC02) Participants indicated that prior experiences with physical therapy (or other therapies) influenced client expectations of the clinical encounter.

While participants indicated that they placed responsibility on the client to engage in management, their narratives suggested that they viewed themselves as having an important role in supporting clients to participate in management.

\section{Client beliefs about $0 \mathrm{~A}$}

Participants explained some clients had misconceptions about OA, believing that there was nothing they could do to manage symptoms or normalising it as part of ageing. One participant explained: "People just accept that they have pain, because they've been told they have arthritis and they don't understand there are things they can do." (PC12) Such preconceptions about $\mathrm{OA}$ were perceived to be a barrier to management. Participants indicated that in viewing $\mathrm{OA}$ as a degenerative condition, some clients feared participation in exercise due to concerns it would lead to further degeneration.

Participants believed that accepting a diagnosis of OA could be particularly challenging for people with early OA since X-rays may not show changes. One participant explained: "I think generally with the earlier symptoms of knee $O A$, would be a lack of understanding or to some extent a denial of what that is...I had $x$-rays done and there is nothing, so I can't really having anything and it's not that bad yet." (PC18)

\section{Client characteristics and context}

Participants identified myriad client characteristics and contextual factors which affected management of perceived early knee OA. These included the client's pre-existing activity level, general health (eg, obesity), socioeconomic status, language, family responsibilities, lifestyle and occupation. Sometimes factors acted as a facilitator to management. For example: "If you have an active person, they will do whatever it is they generally can, to try 
and work around it." (PC11) Other factors acted as barriers to management. For example: "People are busy and they have a lot going on, especially if they have young kids or are carting kids all over." (PC24)

\section{DISCUSSION}

To date, there is a paucity of research that has examined the barriers and facilitators affecting OA management by $\mathrm{PTs}^{20}$ and, to our knowledge, no studies have focused on management of perceived early knee OA. Amid the increasing emphasis on early initiation of treatment for $\mathrm{OA},{ }^{1415}$ it is important to understand the specific contextual factors affecting implementation of OA management for this population. The findings provide us with a basis to address specific implementation problems and to optimise care. We identified factors which were primarily enablers of management: PTs' confidence in their abilities to manage perceived early knee OA, PTs' beliefs about consequences of $\mathrm{OA}$ and scope of practice. We also identified modifiable factors that can be barriers to management in some situations and can be targeted to improve care: availability and timely access to services in the community (eg, exercise programmes) and healthcare system (eg, PTs); healthcare provider factors including time, access to evidence, and physicians' referrals and messaging to clients; and client engagement in management and beliefs about OA. The participant's context (ie, rural/urban, client characteristics, private/ public) influenced whether a factor acted as a barrier or facilitator of management, highlighting the importance of considering the local context when developing interventions. While it is possible factors identified by participants may not only apply to early knee OA (ie, apply to all OA), some of the factors are particularly relevant if we are to optimise PTs' management of early knee OA. These include timely access to physical therapy, physician messaging about OA and timeliness of referrals, PTs' beliefs about the consequences of $\mathrm{OA}$, client beliefs and client engagement in management. As such, these factors are the focus of the discussion.

Participants believed that lack of access to PTs was a key barrier to providing management at an early stage of OA. They consistently expressed concerns that some people could not access care or delayed seeking help due to financial barriers. In Canada, the public-private mix for physiotherapy has been shifting with $49 \%$ of PTs working in the public sector compared with $51 \%$ in the private sector. ${ }^{32}$ Scholars have pointed out the potential for unequal access to PTs in this increasingly user pay system. ${ }^{33}$ When Ontario, Canada's most populous province, partially delisted publicly funded community-based physical therapy services by restricting the eligibility criteria, one study showed that 20 of 113 people (17.7\%) required services but did not receive them after delisting. ${ }^{34}$ While physical therapy is funded for people over age 65 in Ontario, this may be too late for some people with $\mathrm{OA}$, for whom early symptoms may begin in the third or fourth decade of life. ${ }^{35}$ Policies and new models of service delivery are needed to ensure timely access to PTs for individuals with OA across the disease spectrum and lifespan.

While PTs in Canada have direct access, some participants identified that the physician remained an important factor in OA management, both in terms of appropriately referring clients with perceived early knee $\mathrm{OA}$ and messaging to clients. Research suggests that some patients continue to perceive that doctors "know best' ${ }^{36}$ Yet, research has shown that general practitioners sometimes believe OA is an inevitable disease of ageing and trivialise it in practice. ${ }^{20}{ }^{37}$ Our study highlights that physicians' referrals and messaging can be a detriment to early intervention by PTs. Their messages to clients can have ripple effects that impact the ability of PTs to deliver evidence-based management, such as exercise. Initiatives to improve physicians' knowledge of $\mathrm{OA}$, including when and to whom to refer clients for non-pharmacological management, are warranted to ensure clients with early knee OA are referred in a timely way.

Existing research suggests that PTs experienced challenges in supporting behaviour change, lacking the requisite knowledge. ${ }^{38}$ Our participants' accounts suggested that it could be challenging for them to motivate clients to engage in management. Supporting behaviour change is critical since studies show that adherence to exercise improves pain and disability ${ }^{39} 40$ but tends to wane over time. ${ }^{41}$ A Cochrane review examining interventions to improve adherence to exercise in OA found that motivational strategies showed promise. ${ }^{42}$ Motivational interviewing, a common behaviour change technique (BCT) used by health professionals, has improved outcomes, such as treatment adherence, health behaviours and clinical outcomes in people with conditions such as chronic pain, type 2 diabetes, cancer and obesity and may be a promising intervention. ${ }^{43-46}$ Recently, Nicolson et $a t^{47}$ surveyed physiotherapists about their experience with BCTs. Education was most commonly used despite research showing that providing information is inadequate to change behaviour. ${ }^{48}$ Our research adds further evidence for the need for more support for PTs to use BCTs, like motivational interviewing, effectively in their practice.

Participants perceived that client beliefs influenced management suggesting some clients normalised OA, believing nothing could be done about symptoms, and other clients were reluctant to accept an OA diagnosis, particularly when X-rays do not show changes in the early stages of the disease. In existing qualitative studies from the perspective of people with OA, findings are variable. In some research, older adults normalised $\mathrm{OA}$ as part of ageing. ${ }^{49}$ In contrast, a study of younger adults $(<65$ years) with mild-to-moderate knee OA symptoms did not normalise symptoms. However, younger adults believed there were few management options available to them. ${ }^{31}$ Our participants also perceived that some clients believed that exercise might result in further 'degeneration'. This 
is consistent with studies of people with OA which found that some people have fears that exercise is damaging to their joints ${ }^{50}$ or will worsen pain. ${ }^{51}$ Overcoming misconceptions about OA may require more emphasis on public education that highlights the early signs and symptoms, de-emphasises the need for X-ray findings to diagnose early OA, challenges the assumption that all OA is inevitably progressive and explains the benefits of exercise. Effective, collaborative patient-provider communication about OA management is also crucial.

In a review synthesising primary care clinicians' (predominantly physicians) views on providing OA management, the researchers were unable to identify any themes that represented enablers of management. ${ }^{20}$ In contrast, we identified factors which acted primarily as enablers of management of perceived early knee OA. Participants were confident in their capabilities to manage perceived early knee OA. They also consistently believed that management could improve early symptoms, often citing exercise as recommended treatment. Exercise is recommended as first-line management in all evidencebased guidelines for knee $\mathrm{OA}^{7}$ and while studies specific to early knee OA are scarce, research has shown benefits of exercise in early knee OA. ${ }^{52}$ This is encouraging since healthcare providers' beliefs have been associated with the beliefs and clinical management of their patients. ${ }^{53}$ In contrast, findings from a survey of UK-based PTs from 2009 found that PTs believed that knee OA would worsen, regardless of physical therapy and that exercise could make symptoms worse. ${ }^{38}$ It is important to note that while participants believed management could improve symptoms of early knee OA, they often indicated that OA would progress with no treatment. Cohort studies have begun to challenge the assumption that $\mathrm{OA}$ is slowly progressive by showing that pain changes little over time in the majority of individuals. ${ }^{545}$ As evidence related to our understanding of early knee $\mathrm{OA}$ and the trajectory of $\mathrm{OA}$ accumulates, effective knowledge translation of the evidence to healthcare providers will be necessary.

\section{Strengths and limitations}

This research was informed by theory and, in future, themes can be matched to TDF domains to identify BCTs which may be effective (by linking barriers to intervention components). ${ }^{27}$ The study also has limitations. At the time of the study, there was no universally agreed upon definition of early knee OA. We focused on what participants perceived as early knee OA and used vignettes to help guide discussions about management. Since participants in this sample were mainly recruited through a professional association specialising in orthopaedic physiotherapy and were an experienced sample, working an average of 21 years, it is possible that their perceptions may not reflect the perspectives of all PTs, particularly those in their early career. Finally, this research was situated in the Canadian healthcare system and some factors may apply more to this context.

\section{CONCLUSION}

We have identified barriers and facilitators to PTs' management of early knee OA which have important implications for policy and practice. Factors that are particularly relevant across settings and critical to address to optimise intervention for early OA include timely access to physical therapy, physician messaging about $\mathrm{OA}$ and timeliness of referrals, client beliefs (and misconceptions of OA) and client engagement in management. Addressing these barriers will require a multipronged approach, targeted at both the healthcare system and healthcare providers. Future research is warranted to examine models of service delivery to optimise timely access to PTs and to test BCTs that have potential to optimise management of early knee OA by healthcare providers.

Acknowledgements We would like to thank all study participants for participating in the interviews and Dr Victoria Young for coding a subset of the transcripts.

Contributors CM, GAH and SBJ conceived of and designed the study; CM collected the data; CM, GAH and SBJ contributed to the analysis and interpretation of the data; $\mathrm{CM}$ drafted the manuscript and all authors reviewed and provided comments on the manuscript.

Funding CM is supported by a Postdoctoral Fellowship from the Canadian Institutes of Health Research. SBJ is supported by the Toronto Rehabilitation Institute Chair at the University of Toronto. GAH holds the Sir John and Lady Eaton Professor and Chair of the Department of Medicine, University of Toronto.

Competing interests None declared.

Patient consent Not required.

Ethics approval University of Toronto Research Ethics Board.

Provenance and peer review Not commissioned; externally peer reviewed. Data sharing statement № additional data are available.

Open access This is an open access article distributed in accordance with the Creative Commons Attribution Non Commercial (CC BY-NC 4.0) license, which permits others to distribute, remix, adapt, build upon this work non-commercially, and license their derivative works on different terms, provided the original work is properly cited, appropriate credit is given, any changes made indicated, and the use is non-commercial. See: http://creativecommons.org/licenses/by-nc/4.0/.

\section{REFERENCES}

1. Vos T, Flaxman AD, Naghavi M, et al. Years lived with disability (YLDs) for 1160 sequelae of 289 diseases and injuries 1990-2010: a systematic analysis for the Global Burden of Disease Study 2010. Lancet 2012;380:2163-96.

2. World Health Organization. Chronic rheumatic conditions, 2018

3. Christensen R, Bartels EM, Astrup A, et al. Effect of weight reduction in obese patients diagnosed with knee osteoarthritis: a systematic review and meta-analysis. Ann Rheum Dis 2007;66:433-9.

4. Fransen M, McConnell S, Harmer AR, et al. Exercise for osteoarthritis of the knee. Cochrane Database Syst Rev 2015;1:CD004376.

5. Fernandes L, Hagen KB, Bijlsma JW, et al. EULAR recommendations for the non-pharmacological core management of hip and knee osteoarthritis. Ann Rheum Dis 2013;72:1125-35.

6. Hochberg MC, Altman RD, April KT, et al. American College of Rheumatology 2012 recommendations for the use of nonpharmacologic and pharmacologic therapies in osteoarthritis of the hand, hip, and knee. Arthritis Care Res 2012;64:465-74.

7. McAlindon TE, Bannuru RR, Sullivan MC, et al. OARSI guidelines for the non-surgical management of knee osteoarthritis. Osteoarthritis Cartilage 2014;22:363-88.

8. Nelson AE, Allen KD, Golightly YM, et al. A systematic review of recommendations and guidelines for the management of osteoarthritis: the chronic osteoarthritis management initiative of the U.S. bone and joint initiative. Semin Arthritis Rheum 2014;43:701-12.

9. Hagen KB, Smedslund G, Østerås N, et al. Quality of communitybased osteoarthritis care: a systematic review and meta-analysis. Arthritis Care Res 2016;68:1443-52. 
10. Li LC, Sayre EC, Kopec JA, et al. Quality of nonpharmacological care in the community for people with knee and hip osteoarthritis. $J$ Rheumatol 2011;38:2230-7.

11. McHugh GA, Campbell M, Luker KA. Quality of care for individuals with osteoarthritis: a longitudinal study. J Eval Clin Pract 2012;18:534-41.

12. Broadbent J, Maisey S, Holland R, et al. Recorded quality of primary care for osteoarthritis: an observational study. Br J Gen Pract 2008:58:839-43.

13. MacKay C, Badley EM, Jaglal SB, et al. "We're all looking for solutions": a qualitative study of the management of knee symptoms. Arthritis Care Res 2014;66:1033-40.

14. Luyten FP, Bierma-Zeinstra S, Dell'Accio F, et al. Toward classification criteria for early osteoarthritis of the knee. Semin Arthritis Rheum 2018;47.

15. Madry H, Kon E, Condello V, et al. Early osteoarthritis of the knee. Knee Surg Sports Traumatol Arthrosc 2016;24:1753-62.

16. Bennell KL, Hinman RS, Metcalf BR, et al. Efficacy of physiotherapy management of knee joint osteoarthritis: a randomised, double blind, placebo controlled trial. Ann Rheum Dis 2005;64:906-12.

17. Hurley MV, Walsh NE, Mitchell HL, et al. Clinical effectiveness of a rehabilitation program integrating exercise, self-management, and active coping strategies for chronic knee pain: a cluster randomized trial. Arthritis Rheum 2007;57:1211-9.

18. Skou ST, Roos EM. Good Life with osteoArthritis in Denmark (GLA:D): evidence-based education and supervised neuromuscular exercise delivered by certified physiotherapists nationwide. BMC Musculoskelet Disord 2017;18:72.

19. Holden MA, Nicholls EE, Hay EM, et al. Physical therapists' use of therapeutic exercise for patients with clinical knee osteoarthritis in the United kingdom: in line with current recommendations? Phys Ther 2008;88:1109-21.

20. Egerton T, Diamond LE, Buchbinder R, et al. A systematic review and evidence synthesis of qualitative studies to identify primary care clinicians' barriers and enablers to the management of osteoarthritis. Osteoarthritis Cartilage 2017;25:625-38.

21. Sandelowski M. Whatever happened to qualitative description? Res Nurs Health 2000;23:334-40.

22. Tong A, Sainsbury P, Craig J. Consolidated criteria for reporting qualitative research (COREQ): a 32-item checklist for interviews and focus groups. Int J Qual Health Care 2007;19:349-57.

23. MacKay C, Jaglal SB, Sale J, et al. A qualitative study of the consequences of knee symptoms: 'It's like you're an athlete and you go to a couch potato'. BMJ Open 2014;4:e006006.

24. Boscart VM, Fernie GR, Lee JH, et al. Using psychological theory to inform methods to optimize the implementation of a hand hygiene intervention. Implement Sci 2012;7:77.

25. Heslehurst N, Newham J, Maniatopoulos G, et al. Implementation of pregnancy weight management and obesity guidelines: a metasynthesis of healthcare professionals' barriers and facilitators using the Theoretical Domains Framework. Obes Rev 2014;15:462-86.

26. McSherry LA, Dombrowski SU, Francis JJ, et al. 'It's a can of worms': understanding primary care practitioners' behaviours in relation to HPV using the Theoretical Domains Framework. Implement Sci 2012;7:73.

27. Cane J, O'Connor D, Michie S. Validation of the theoretical domains framework for use in behaviour change and implementation research Implement Sci 2012;7:37.

28. Michie S, Johnston M, Francis J, et al. From Theory to Intervention: Mapping Theoretically Derived Behavioural Determinants to Behaviour Change Techniques. Appl Psychol 2008:57:660-80.

29. Holt A. Using the telephone for narrative interviewing: a research note. Qualitative Research 2010;10:113-21.

30. Braun V, Clarke V. Using thematic analysis in psychology. Qual Res Psychol 2006;3:77-101.

31. MacKay C, Sale J, Badley EM, et al. Qualitative Study Exploring the Meaning of Knee Symptoms to Adults Ages 35-65 Years. Arthritis Care Res 2016;68:341-7.

32. Canadian Institute for Health Information. Physiotherapists, 2015, 2017.

33. Hogg-Johnson S, Cole DC, Lee H, et al. Changes in physiotherapy utilization in one workforce: implications for accessibility among canadian working-age adults. Healthc Policy 2011;6:93-108.

34. Landry MD, Deber RB, Jaglal S, et al. Assessing the consequences of delisting publicly funded community-based physical therapy on self-reported health in Ontario, Canada: a prospective cohort study. Int J Rehabil Res 2006;29:303-7.

35. Kopec JA, Rahman MM, Berthelot JM, et al. Descriptive epidemiology of osteoarthritis in British Columbia, Canada. $J$ Rheumatol 2007;34:386-93.

36. Joseph-Williams N, Elwyn G, Edwards A. Knowledge is not power for patients: a systematic review and thematic synthesis of patientreported barriers and facilitators to shared decision making. Patient Educ Couns 2014;94:291-309.

37. Alami S, Boutron I, Desjeux D, et al. Patients' and practitioners' views of knee osteoarthritis and its management: a qualitative interview study. PLoS One 2011;6:e19634.

38. Holden MA, Nicholls EE, Young J, et al. UK-based physical therapists' attitudes and beliefs regarding exercise and knee osteoarthritis: findings from a mixed-methods study. Arthritis Rheum 2009;61:1511-21.

39. Marks R. Knee osteoarthritis and exercise adherence: a review. Curr Aging Sci 2012;5:72-83.

40. Thomas KS, Muir KR, Doherty M, et al. Home based exercise programme for knee pain and knee osteoarthritis: randomised controlled trial. BMJ 2002;325:752.

41. Campbell R, Evans M, Tucker M, et al. Why don't patients do their exercises? Understanding non-compliance with physiotherapy in patients with osteoarthritis of the knee. J Epidemiol Community Health 2001;55:132-8.

42. Jordan JL, Holden MA, Mason EE, et al. Interventions to improve adherence to exercise for chronic musculoskeletal pain in adults. Cochrane Database Syst Rev 2010;1:CD005956.

43. Alperstein $D$, Sharpe $L$. The efficacy of motivational interviewing in adults with chronic pain: a meta-analysis and systematic review. $J$ Pain 2016;17:393-403

44. Armstrong MJ, Mottershead TA, Ronksley PE, et al. Motivational interviewing to improve weight loss in overweight and/or obese patients: a systematic review and meta-analysis of randomized controlled trials. Obes Rev 2011;12:no-723.

45. Ekong G, Kavookjian J. Motivational interviewing and outcomes in adults with type 2 diabetes: A systematic review. Patient Educ Couns 2016;99:944-52.

46. Spencer JC, Wheeler SB. A systematic review of motivational Interviewing interventions in cancer patients and survivors. Patient Educ Couns 2016;99:1099-105.

47. Nicolson PJA, Hinman RS, French SD, et al. Improving Adherence to Exercise: Do People With Knee Osteoarthritis and Physical Therapists Agree on the Behavioral Approaches Likely to Succeed? Arthritis Care Res 2018;70:388-97.

48. Roter DL, Hall JA, Merisca R, et al. Effectiveness of interventions to improve patient compliance: a meta-analysis. Med Care 1998;36:1138-61.

49. Sanders C, Donovan J, Dieppe P. The significance and consequences of having painful and disabled joints in older age: coexisting accounts of normal and disrupted biographies. Sociology of Health \& IIIness 2002;24:227-53.

50. Hendry M, Williams NH, Markland D, et al. Why should we exercise when our knees hurt? A qualitative study of primary care patients with osteoarthritis of the knee. Fam Pract 2006;23:558-67.

51. Spitaels D, Vankrunkelsven P, Desfosses J, et al. Barriers for guideline adherence in knee osteoarthritis care: A qualitative study from the patients' perspective. J Eval Clin Pract 2017:23:165-72.

52. McKnight PE, Kasle S, Going S, et al. A comparison of strength training, self-management, and the combination for early osteoarthritis of the knee. Arthritis Care Res 2010;62:45-53.

53. Darlow B, Fullen BM, Dean S, et al. The association between health care professional attitudes and beliefs and the attitudes and beliefs, clinical management, and outcomes of patients with low back pain: a systematic review. Eur J Pain 2012;16:3-17.

54. Collins JE, Katz JN, Dervan EE, et al. Trajectories and risk profiles of pain in persons with radiographic, symptomatic knee osteoarthritis: data from the osteoarthritis initiative. Osteoarthritis Cartilage 2014;22:622-30.

55. Nicholls E, Thomas E, van der Windt DA, et al. Pain trajectory groups in persons with, or at high risk of, knee osteoarthritis: findings from the Knee Clinical Assessment Study and the Osteoarthritis Initiative. Osteoarthritis Cartilage 2014;22:2041-50. 